\title{
CORRECTION
}

\section{Correction to: Mirogabalin: First Global Approval}

\author{
Emma D. Deeks ${ }^{1}$
}

Published online: 26 February 2019

(c) Springer Nature Switzerland AG 2019

\section{Correction to: Drugs}

https://doi.org/10.1007/s40265-019-01070-8

Table 'Key clinical trials of mirogabalin'.

The title, which currently reads:

Key clinical trials of mirogabalin (Daiichi Sankyo Inc).

Should read:

Key clinical trials of mirogabalin (Daiichi Sankyo Inc, and Daiichi Sankyo Co. Ltd).

The original article can be found online at https://doi.org/10.1007/ s40265-019-01070-8.

Emma D. Deeks

dru@adis.com

1 Springer, Private Bag 65901, Mairangi Bay, Auckland 0754, New Zealand 